\title{
Competitividad estructural de las exportaciones del sector textil mexicano: un análisis comparativo con respecto a sus competidores
}

\author{
Structural competitiveness of the Mexican exports of textiles: A comparative \\ analysis with respect to its competitors
}

\author{
Raúl Vázquez-López* \\ Instituto de Investigaciones Económicas, Universidad Nacional Autónoma de México, México
}

Recibido el 8 de abril de 2019; aceptado el 23 de octubre de 2019

Disponible en Internet el: 23 de octubre de

\section{Resumen}

Este artículo analiza la evolución de las exportaciones del textil mexicano, en términos de la composición de los productos vendidos en Estados Unidos (E.U.) y la Unión Europea (U.E.), de 1994 a 2015, comparando su desempeño con respecto al de sus competidores. La aplicación de una técnica estadística diferencial-estructural revela la inexistencia de un cambio estructural cualitativo relevante, que permitiera generar capacidades tendientes a desarrollar ventajas competitivas en productos alternativos de mayor valor agregado al amparo del TLCAN. Comparativamente, en el caso chino, el perfil competitivo fue diversificándose en dirección de productos más sofisticados en una senda de escalamiento productivo. En cuanto a las exportaciones mexicanas al mercado europeo, los hallazgos obtenidos muestran indicios de una transformación regresiva, en la que las ventas de prendas de vestir, originalmente destinadas a E.U., fueron re direccionadas hacia la U.E., en detrimento de la profundización de las exportaciones de insumos de mayor valor agregado.

Código JEL: L67, F14, F63, L16, O24

Palabras clave: México; Competitividad; Exportaciones; Textil; TLCAN

\footnotetext{
*Autor para correspondencia

Correo electrónico ravazz@ hotmail.com (R. Vázquez-López).

La revisión por pares es responsabilidad de la Universidad Nacional Autónoma de México. 


\begin{abstract}
This article analyzes the evolution of the Mexican exports of textiles to the United States (U.S.) and the European Union (E.U.) markets in the period 1994-2015, in terms of the composition of products exported to those destinations, by comparing its performance with respect to their main competitors in each case. A shift-share approach shows that despite NAFTA's protection, there was no relevant structural change in the composition of Mexican exports leading to the generation of new capabilities oriented to develop competitive advantages in more sophisticated products. On the contrary, Chinese competitive profile changed towards more sophisticated products on those markets following a planned upgrading path. As for the E.U. market, results show that Mexican exports experienced a regressive transformation as clothing exports to the U.S were redirected to the E.U. in detriment of the deepening of higher value added exports of elaborated intermediate goods.
\end{abstract}

JEL codes: L67, F14, F63, L16, O24

Keywords: Mexico; Competitiveness; Exports; Textile; Nafta

\title{
Introducción
}

A finales de los años ochenta del siglo pasado, México abandona la estrategia de industrialización por sustitución de importaciones, en favor de un modelo de corte ortodoxo que promueve la desregulación de la economía y una apertura comercial acelerada. En este nuevo patrón de especialización y competitividad, el comercio exterior se concibe como la principal palanca de cambio estructural y de desarrollo, lo que se traduce en la implementación de diversos programas públicos de apoyo a la competitividad externa asociados a los regímenes arancelarios específicos de la industria maquiladora de exportación y al Programa de Importación Temporal para producir Artículos de Exportación (PITEX) (Puyana y Romero, 2006; Vázquez, 2012). Como punto culminante, la entrada en vigor del Tratado de Libre Comercio para América del Norte (TLCAN) en 1994, significa la integración definitiva de la economía mexicana en una división regional del trabajo, capitaneada por las estrategias de grandes grupos transnacionales, nuevos actores centrales en el patrón de competitividad, y representa el ingreso de elevados montos de inversión extranjera al país bajo la forma de empresas ensambladoras en sectores líderes específicos como el automotriz (Capdevielle, Cimoli, y Dutrenit, 1997).

Como resultado, el peso del sector externo se incrementa y las exportaciones mexicanas ligadas a procesos globales crecen a tasas elevadas, concentrándose en un número de productos cada vez más reducido, vendidos principalmente en un solo mercado, el de los Estados Unidos (Capdevielle, 2005). A partir del desarrollo de la maquila en la frontera norte, y de la mano de la incorporación de las empresas mexicanas en cadenas regionales de valor altamente jerarquizadas, México se transforma rápidamente en un enclave exportador, cuyo 
éxito se origina en tres ventajas competitivas centrales, el bajo costo de la mano de obra, la ubicación geográfica, y la existencia del TLCAN que permite la exportación de productos desde el territorio nacional hacia Estados Unidos, al amparo de los regímenes arancelarios específicos. No obstante, y contrariamente a los supuestos teóricos, el éxito exportador no se traduce en un crecimiento sostenible del PIB y del empleo, y es incluso incapaz de contrarrestar el aumento de las importaciones (Romero, Puyana, y Dieck, 2005).

De manera emblemática, en el caso del sector textil, el dinamismo exportador, en los años noventa, se produce a partir de enclaves maquiladores en el norte del país, resultado de una estrategia de reducción de costos globales, por parte de grandes empresas transnacionales norteamericanas, enfrentadas a la competencia de países asiáticos (González, 2004). De los 1789 millones de dólares de inversión extranjera directa dirigidos a la industria textil y del vestuario entre enero de 1994 y septiembre de 2001, más del 80\% proviene de Estados Unidos (García de León, 2008). Conforme el sector textil mexicano se va insertando en la lógica productiva regional, marcada por la segmentación del proceso productivo y la posterior deslocalización de tareas a nivel internacional, se producen transformaciones irreversibles. A la par del desarrollo de complejos industriales exitosos, como es el caso de la región de la Laguna, que se convierte rápidamente en la capital de la mezclilla, las PYMES entran en procesos de quiebra y bancarrota o en el mejor de los casos transitan a la informalidad al dispersar su producción en talleres y domicilios en el ámbito rural (Taboada, 2000).

Estos cambios se aceleran a raíz de la expiración del Acuerdo sobre Textiles y el Vestido $(\mathrm{ATV})^{1}$ en 2005 que significa el fin de una estricta regulación de los flujos internacionales de bienes, a través del principio de cuotas discriminatorias a la entrada de los principales mercados. La desaparición de los sistemas de cuotas se traduce en una redoblada competencia, particularmente entre los países de bajos costos, y resulta en sobreproducción en el sector, y en crecientes exigencias por parte de la gobernanza de las cadenas regionales de valor en términos de capacidades para los proveedores (acceso a insumos y transporte y capacidades de diseño y adaptación de nuevas tecnologías, entre otras) (Cárdenas y Dussel, 2007). En la práctica, la cancelación de las ventajas arancelarias otorgadas por el TLCAN significa el incremento de las cuotas del mercado de Estados Unidos de los países asiáticos, y en especial de China, así como el desplazamiento de un gran número de proveedores mexicanos incapaces de incrementar su inversión en tecnología y procesos organizativos, llevando incluso a la declinación a los complejos industriales más exitosos como el de la Laguna (Morales, Parker, y Saavedra, 2010).

En este contexto, resulta de especial interés realizar un diagnóstico, de tipo estructural, que permita detectar las carencias específicas de la estrategia sectorial establecida, tanto a

\footnotetext{
${ }^{1}$ Establecido de 1995 a 2004 por la Organización Mundial del Comercio (OMC) en sustitución del Acuerdo Multifibras (1974-1994) y en calidad de periodo de transición hacia la liberalización total del sector.
} 
nivel de grupo de productos, como en comparación con los principales competidores del país en los mercados de mayor tamaño (Estados Unidos y la Unión Europea).

\section{Antecedentes y objetivos}

Una primera aproximación al desempeño externo del sector textil mexicano sugiere una evolución marcada por tres etapas. Entre 1994 y el año 2000, el valor de las exportaciones se multiplica por 4.5 veces, producto de la apertura comercial y de una inserción del sector en redes regionales de valor que permite un incipiente y localizado escalamiento de las capacidades en términos de innovaciones de proceso, productos y organizacionales, en dirección de modelos de negocio en los que se integran las tareas que van desde la fabricación de la tela hasta las de empaquetado y distribución (Taboada, 2000). En un segundo lapso, una vez agotadas las posibilidades de dicho proceso y con la liberalización total del comercio internacional en el sector que significa el desplazamiento de las industrias proveedoras mexicanas por extranjeras en el seno de estas redes, las ventas sectoriales al exterior se desploman, pasando de 10 986 millones de dólares en el año 2000 a 5536 millones en 2009. A partir de ese año y tras la desindustrialización de ramas enteras del textil mexicano, las exportaciones se estabilizan registrando un valor de 6730 millones de dólares en 2015 (Figura 1).

El deterioro competitivo del textil mexicano a partir del año 2000, se da de la mano de un elevado grado de concentración de las exportaciones tanto en términos de los mercados de destino como en lo relativo a los productos comerciados. En 1994, 89.7\% de las exportaciones sectoriales se dirigen al mercado de los Estados Unidos y el 54.4\% son prendas de vestir (categoría 1810), para el año 2015, estos porcentajes se ubican en valores de $89.4 \%$ y $47.6 \%$ respectivamente. Cabe señalar que, para el último año de la serie (2015), tres categorías de productos, Fabricación de prendas de vestir, Fabricación de artículos confeccionados de materiales textiles (1721), y Fabricación de tejidos y artículos de punto y ganchillo (1730), suman $83.3 \%$ de las exportaciones sectoriales (Tabla 1). Como en el caso del resto del comercio exterior mexicano, esta elevada concentración de las ventas al exterior implica una mayor vulnerabilidad ante los cambios en la demanda y en los precios de este tipo de productos en el mercado de los E.U. De hecho, en la literatura económica, uno de los mecanismos de transmisión claramente identificados entre la diversificación de las exportaciones y el crecimiento económico, es el "efecto cartera", que, por oposición, fomenta una menor volatilidad de las exportaciones, y de los ingresos provenientes de las mismas, repercutiendo positivamente en el nivel y constancia del crecimiento del PIB (Stanley y Bunnag, 2001; Strobl, Bertinelli, y Heinen, 2009). 


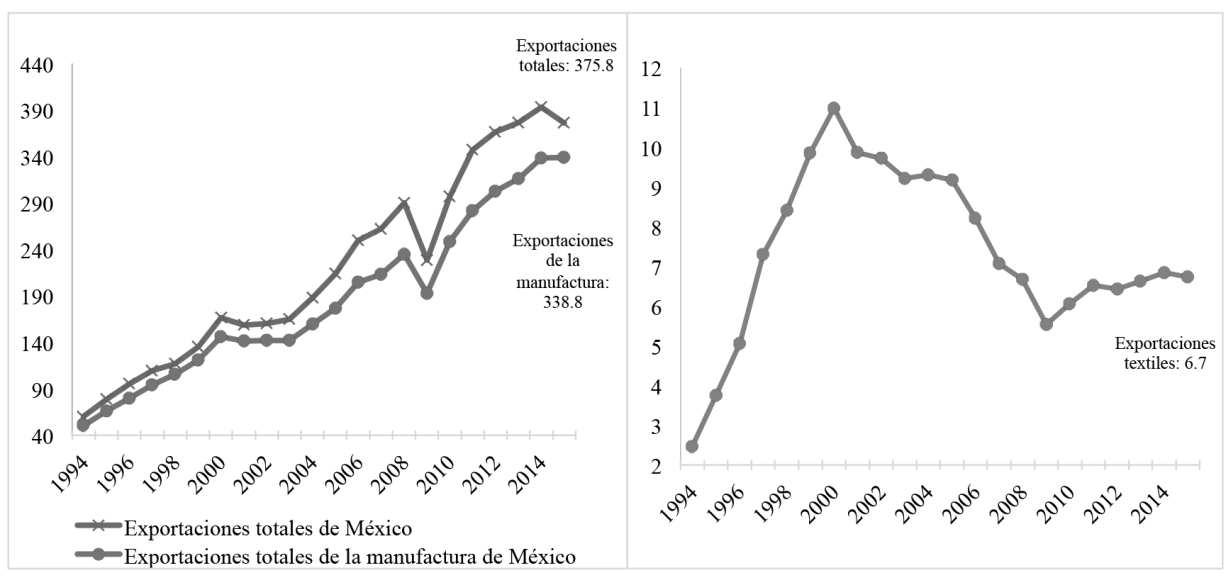

Figura 1. Exportaciones totales, manufactureras, y textiles de México, 1994-2015

(miles de millones de dólares)

Fuente: Elaboración propia con datos de ONU (2018), COMTRADE, descargados con el programa

WITS del Banco Mundial.

Tabla 1

Estructura de las exportaciones textiles mexicanas al mundo por categoría de productos, 1994-2015 (miles de millones de dólares y porcentajes)

\begin{tabular}{lccccc}
\hline Años/Categoría & 1994 & 2000 & 2005 & 2010 & 2015 \\
Exportaciones totales & 2.45 & 10.99 & 9.17 & 6.05 & 6.73 \\
Hilatura, tejedura y acabado de productos textiles & 14.33 & 8.25 & 5.27 & 6.41 & 7.55 \\
$\begin{array}{l}\text { Fabricación de artículos confeccionados de materiales textiles, } \\
\text { excepto prendas de vestir }\end{array}$ & 14.62 & 8.99 & 9.70 & 13.52 & 17.11 \\
Fabricación de tapices y alfombras & 2.69 & 0.65 & 0.61 & 0.59 & 0.82 \\
Fabricación de cuerdas, cordeles, bramantes y redes & 0.91 & 0.57 & 0.88 & 1.18 & 1.13 \\
Fabricación de otros productos textiles & 3.57 & 3.13 & 3.58 & 6.28 & 7.16 \\
Fabricación de tejidos y artículos de punto y ganchillo & 9.51 & 17.87 & 16.97 & 20.54 & 18.60 \\
Fabricación de prendas de vestir, excepto prendas de piel & 54.38 & 60.54 & 62.99 & 51.48 & 47.63 \\
Total & 100 & 100 & 100 & 100 & 100 \\
\hline
\end{tabular}

Fuente: Elaboración propia con datos de ONU (2018), COMTRADE, descargados con el programa WITS del Banco Mundial. 
Estructuralmente, el deterioro de la competitividad del textil mexicano, a raíz de la liberalización comercial del sector a nivel mundial, se traduce en una reducción de la parte de las exportaciones de prendas de vestir, categoría de productos de ensamblaje ligada a la actividad de redes regionales de fabricación, capitaneadas por grandes empresas transnacionales de los E.U., en favor de las participaciones de las ventas de artículos confeccionados de materiales textiles (1721) y de otros productos textiles (1729) en las exportaciones totales (Tabla 1). Este desplazamiento compensatorio es concomitante de un fuerte incremento de la parte de las exportaciones de prendas de vestir en las ventas sectoriales realizadas a la U.E., de $32 \%$ en 2005 a $61.4 \%$ en 2015. Lo anterior, a pesar de no resultar significativo en términos absolutos para el comercio del sector, y no permitir compensar la pérdida registrada en el mercado del principal socio comercial, pone en relieve el rol potencial del mercado de la U.E., en calidad de elemento de diversificación de los destinos de exportación y en consecuencia de estabilización de los ingresos de la actividad exportadora.

En el mercado de los E.U., la pérdida de competitividad del textil mexicano está asociada al fuerte incremento de la cuota de mercado de China tras la liberalización comercial. En el año 2000, la participación de las ventas sectoriales en E.U. de México y China eran prácticamente idénticas tanto a nivel general (13.2\%), como en los principales productos exportados (en la categoría 1810 ambas naciones ostentaban una cuota de alrededor de 14\%). Para el año 2010, una vez liberalizado totalmente el comercio mundial en el sector, China controla casi la mitad del principal mercado del mundo (41.4\%) seguida muy de lejos por México (4.9\%) y la India (4.8\%) (Figura 2). La fuerte reducción de la cuota mexicana se explica mayoritariamente, por la sustitución de contratistas mexicanos por chinos en la lógica de funcionamiento de las redes regionales de fabricación en búsqueda de factores de competitividad más complejos (flexibilidad, calidad, capacidades de diseño y desarrollo del producto) (García de León, 2009).

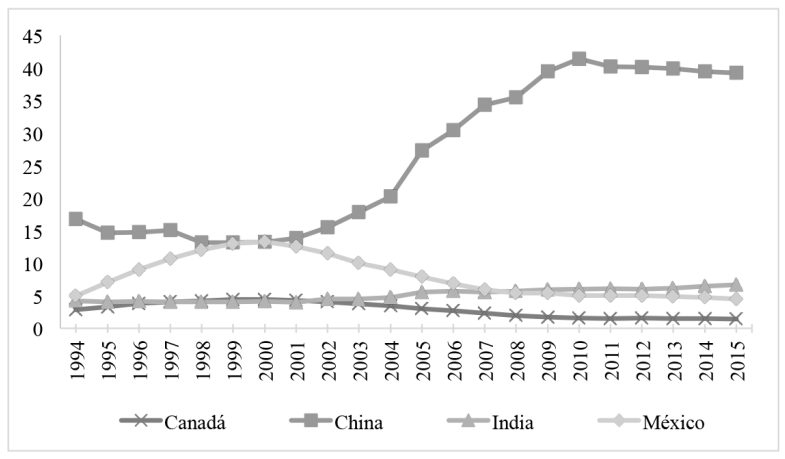

Figura 2. Cuotas del mercado de los Estados Unidos por país, 1994-2015 (porcentajes) Fuente: Elaboración propia con datos de ONU (2018), COMTRADE, descargados con el programa WITS del Banco Mundial. 
A nivel de categorías de productos, como es de esperarse, los países han desarrollado ventajas competitivas específicas en función de sus capacidades tecnológicas y organizativas con independencia del mercado de destino de sus exportaciones. De esta forma, mientras China ha incrementado sus cuotas del mercado de E.U. y la U.E., particularmente en las ventas de artículos confeccionados de materiales textiles (1721), en las que controla en 2015 , $59 \%$ del mercado de los E.U., la India ha profundizado su presencia en dichos destinos vía las exportaciones de tapices y alfombras (1722) (Tabla 2). México, por el contrario, muestra un patrón de especialización determinado por su ubicación geográfica, y dependiente de la demanda de los E.U., en el que los otros destinos de exportación no han sido explotados. En suma, la organización regional productiva articulada alrededor el TLCAN, y marcada por la segmentación del proceso de fabricación en tareas, ha impedido la generación de ventajas competitivas sostenibles en determinados tipos de productos.

Tabla 2

Cuotas de los mercados de E.U y la U.E* por países y categorías de productos, 2015 (porcentajes)

\begin{tabular}{|c|c|c|c|c|c|c|}
\hline \multirow{2}{*}{ Categorías } & \multicolumn{2}{|c|}{ México } & \multicolumn{2}{|c|}{ China } & \multicolumn{2}{|c|}{ India } \\
\hline & E.U. & U.E. & E.U. & U.E. & E.U. & U.E. \\
\hline Exportaciones totales & 4.48 & 0.10 & 39.25 & 38.00 & 6.66 & 7.48 \\
\hline Hilatura, tejedura y acabado de productos textiles & 5.30 & 0.13 & 26.54 & 32.68 & 10.79 & 8.90 \\
\hline $\begin{array}{l}\text { Fabricación de artículos confeccionados de materiales } \\
\text { textiles, excepto prendas de vestir }\end{array}$ & 5.62 & 0.12 & 58.97 & 46.21 & 15.10 & 10.66 \\
\hline Fabricación de tapices y alfombras & 0.96 & 0.06 & 23.31 & 23.42 & 34.05 & 25.28 \\
\hline Fabricación de cuerdas, cordeles, bramantes y redes & 8.02 & 0.15 & 43.64 & 39.18 & 3.81 & 6.65 \\
\hline Fabricación de otros productos textiles & 8.87 & 0.26 & 23.26 & 31.67 & 2.70 & 4.12 \\
\hline Fabricación de tejidos y artículos de punto y ganchillo & 3.57 & 0.08 & 33.89 & 32.31 & 3.11 & 4.96 \\
\hline $\begin{array}{l}\text { Fabricación de prendas de vestir, excepto prendas de } \\
\text { piel }\end{array}$ & 4.28 & 0.10 & 38.58 & 40.01 & 4.81 & 7.52 \\
\hline
\end{tabular}

*En el caso del mercado de la U.E se excluyen del cálculo las transacciones entre países de la Unión.

Fuente: Elaboración propia con datos de ONU (2018), COMTRADE, descargados con el programa WITS del Banco Mundial. 
Al respecto, la "súbita" pérdida del dinamismo exportador del sector textil mexicano a partir del año 2000, resultado tanto de las transformaciones ocurridas en el ámbito global como de la política pública seguida, evidencia la elevada vulnerabilidad de un modelo de especialización productiva y apertura comercial basado en la explotación de ventajas competitivas estáticas (Vidal, 2014). Desde una perspectiva estructural, y en calidad de insumo para una política pública sectorial alternativa, el presente trabajo busca entonces analizar los principales determinantes de la evolución de las exportaciones de la industria textil mexicana de 1994 a 2015, comparando su desempeño, con respecto al de sus principales competidores, en términos de la composición de los productos vendidos en los mercados de los Estados Unidos y la Unión Europea. Un segundo objetivo es determinar si como resultado de la liberalización internacional del sector, se produjo un cambio estructural cualitativo relevante en el perfil competitivo del país y de ser así, definir sus rasgos principales.

\section{Método y fuentes}

Desde una perspectiva estructural, las mejoras sustantivas en términos de competitividad externa no vienen dadas solamente por aumentos de los ingresos por concepto de ventas al exterior, también requieren una mayor diversificación de las exportaciones, el autodescubrimiento de nuevos productos, la mejora de las capacidades tecnológicas, creciente sofisticación productiva, economías de escala, encadenamientos domésticos hacia atrás y hacia adelante, y diversos tipos de externalidades pecuniarias y tecnológicas (Aditya y Acharyya, 2013). En este sentido, el trabajo seminal del enfoque sobre la "complejidad" realizado por Hidalgo, Klinger, Barabasi, y Hausmann (2007), defiende que, a nivel global, las economías crecen y se transforman a través del escalamiento de los bienes producidos y exportados, es decir, mediante el desarrollo de las capacidades necesarias a la fabricación de dichos bienes. Estos autores encuentran que los países industrializados ocupan el centro del espacio de productos comerciados a nivel mundial más densamente poblado y compuesto por los sectores más interconectados con el resto de las actividades que son los de maquinaria, productos metálicos, y químicos. Mientras la región del sureste asiático concentra su ventaja comparativa en las zonas de productos textiles y del vestido y en los electrónicos, América Latina ha desarrollado un patrón de especialización aún más periférico centrado en la explotación de productos naturales como la minería y la agricultura. En esta visión, el análisis estructural se realiza mediante el estudio de redes de productos exportados, características de los mismos y en particular, de la densidad de las redes consideradas (Hidalgo y Haussman, 2009).

De manera afín, pero con un procedimiento más sencillo, la técnica diferencial-estructural (shift-share) usada en este trabajo, permite comparar la evolución de la competitividad externa y de la estructura exportadora del sector textil mexicano, con respecto a un grupo de países de 
referencia, formado por México y sus tres principales competidores en cada mercado (Canadá, China, e India en el mercado de los E.U., y China, la India, y Turquía en el mercado de la Unión Europea (U.E.). La técnica diferencial-estructural ha sido tradicionalmente utilizada para estudiar diferencias entre tasas de crecimiento regionales y nacionales en variables tales como el empleo y la productividad. Aunque es una metodología relativamente simple y con ciertas limitaciones, es también una herramienta probada, para aislar tendencias en el comportamiento de series estadísticas, y generar información para la toma de decisiones de política pública, ya que permite interpretar cambios significativos en las estructuras industriales de las economías (Wilson, Chem, Ping, y Robinson, 2005). De hecho, la institución gubernamental regulatoria de la política monetaria de Singapur (Monetary Authority of Singapore, 1998), ha utilizado la técnica shift-share para evaluar la posición competitiva de este país entre 1991 y 1996.

En cuanto a las principales limitaciones de la técnica, son de tipo temporal, teórico y predictivo (Yasin, Alavi, y Lisboa, 2004). En primera instancia, esta técnica no arroja un análisis de causalidad, siendo que no permite identificar de forma irrefutable las razones existentes detrás de las tendencias registradas por los comportamientos competitivos de los países, pero la descomposición de la variable de estudio (en este caso, las exportaciones), en componentes (efectos) específicos, aporta información relevante sobre las características estructurales que determinan los cambios observados. En una segunda instancia, si bien la técnica permite la comparación de los rasgos estructurales de países con distintos grados de crecimiento, otra importante limitación es que no genera estimaciones predictivas de la evolución futura ni de la sostenibilidad de las tendencias observadas en el contexto de características estructurales contrafactuales (Timmer, 1988). Cabe señalar sin embargo que, los resultados arrojados por las muy diversas aplicaciones de la metodología, no han sido a la fecha refutados sólidamente, y en muchos casos han servido, como eficientes herramientas de predicción y planificación. Al respecto, el carácter empírico y acotado de los objetivos planteados por este artículo, hacen del shift-share, el instrumento adecuado tanto por razones teóricas como prácticas.

Por último y en tercera instancia, de acuerdo con Barff y Knight (1988), uno de los aspectos más criticados de esta técnica, está relacionado con el hecho de que examina los cambios económicos registrados en un determinado periodo, tomando por lo general para el ejercicio estadístico solamente datos para el año inicial, y final, lo que puede resultar en un sesgo si los años seleccionados son atípicos. En el caso de las versiones utilizadas para este tipo de trabajos, el procedimiento estándar sería utilizar como referencia para calcular los efectos ocurridos, las exportaciones al inicio del periodo o adoptar por valor de referencia, algún tipo de promedio entre los valores de los distintos años. De existir transformaciones significativas en las estructuras industriales consideradas a lo largo del tiempo, el procedimiento anterior podría no tomar en cuenta, de forma adecuada, el origen de los cambios en las exportaciones totales, subestimando o sobreestimando el efecto interactivo. 
Sin embargo, en el presente trabajo, se emplea la versión "dinámica” más completa de la metodología, desarrollada por Wilson, et al. (2005), a partir de trabajos anteriores (Barf y Knight,1988). Se calculan las tasas de crecimiento de las exportaciones, sus valores de referencia, y en consecuencia los distintos efectos, de forma anual, lo que permite medir de manera acertada los cambios estructurales ocurridos al tomar por referencia para cada año, las exportaciones del año anterior. Esta versión dinámica del shift-share permite entonces que las tasas de crecimiento de las exportaciones y la estructura de las mismas varíen y se actualicen cada año, a partir de los cambios sucesivos en los valores de las exportaciones de cada uno de los países considerados. Como ventaja adicional, al obtener una fotografía ininterrumpida de la evolución del diferencial de exportaciones y de sus componentes anualmente, el análisis ayuda a identificar posibles puntos de quiebre estructurales al interior del periodo de estudio, así como tendencias de mayor calado en la competitividad de las distintas economías (Wilson, et al., 2005).

En el caso de la U.E., los ejercicios se calculan excluyendo las transacciones entre países miembros de la unión, mismos que no han sido considerados como competidores por considerarse que poseen ventajas arancelarias que pueden afectar la lógica del análisis. El cambio en las exportaciones realizadas en la categoría i por la economía j a un destino específico (deij) está dado por la suma de los efectos "compartido" (sij), "estructural" (mij), "competitivo" (cij) e "interactivo" (aij);

$$
\text { deij }=s i j+m i j+c i j+a i j
$$

Dónde e=exportaciones, $\mathrm{i}=$ categoría de productos exportados y j=país competidor. Cada sector de cada país tiene un componente de crecimiento "estándar" (sij) aquí llamado "compartido", al cual se deben agregar las contribuciones positivas o negativas asociadas al desempeño de cada caso (mij+cij+aij). El efecto compartido (sij) representa el cambio en las exportaciones que hubiera ocurrido si la estructura de las exportaciones del país en cuestión hubiera seguido la tendencia del grupo de referencia formado por sus competidores (exportaciones homotéticas éij) y la tasa de crecimiento de sus exportaciones en dicha categoría (rij) hubiera sido igual a la tasa de incremento del grupo de referencia (rio), es decir:

$$
\text { sij=e’ ij.rio dónde e’ ij=eio.eoj/eoo }
$$

eio=exportaciones de i del grupo de referencia o; eoj=exportaciones textiles totales del país en cuestión eoo=exportaciones textiles totales del grupo de referencia 
Si eij - érij es positivo, el país en cuestión está especializado en esa categoría de productos dentro del sector con respecto al grupo de referencia y viceversa si el valor es negativo. En consecuencia, cualquier diferencia entre los cambios en las exportaciones de la categoría i del país j y el "efecto compartido" (sij) representa el "efecto neto" o "efecto diferencial" edij (EN) resultante de las características específicas de cada economía y es medida en términos absolutos en dólares de los E.U. a partir de la siguiente descomposición;

$$
\text { edij=deij-sij=deij-e' ijrio=eijrij-e'ijrio }
$$

Un valor positivo en este diferencial significa una mejora de la competitividad en relación con el grupo de referencia, mientras un valor negativo implica un deterioro de la competitividad. Este diferencial es entonces la sumatoria de tres componentes mij, cij, aij. El efecto estructural (EE) (mij) muestra la parte del diferencial causado, por la divergencia entre la estructura sectorial de exportaciones de la economía en cuestión y la del grupo de referencia. Este efecto es positivo si las categorías dinámicas del sector tienen una participación mayor en las exportaciones, con respecto al grupo de referencia, y es, por el contrario, negativo, si las categorías de lento crecimiento tienen una participación mayor en las exportaciones del sector con respecto al grupo de referencia. El "efecto estructural" se calcula de la siguiente forma;

$$
\text { mij=rio(eij-e' ij) }
$$

Por su parte, el "efecto competitivo" (EC) (cij) muestra la parte del diferencial atribuido a la divergencia, entre la tasa de incremento de las exportaciones de la economía en cuestión y la del grupo de referencia en esa categoría. Este efecto es positivo si la tasa de crecimiento de las exportaciones del país en cuestión es superior a la del grupo de referencia, lo que indica la contribución especial del dinamismo de una categoría de productos al aumento de las exportaciones, es decir evidencia de ventaja competitiva de la economía considerada en estos productos. El "efecto competitivo" se calcula de la siguiente forma;

$$
\text { cij=e'ij(rij-rio) }
$$

Por último, el "efecto interactivo" (EI) (aij) señala la parte del diferencial ocasionado por una combinación de los efectos estructural y competitivo. Este efecto es positivo si la economía en cuestión está especializada en las categorías en las que detenta una ventaja competitiva y exporta más que el grupo de referencia en las categorías de productos en las que ostenta ventaja competitiva. El "efecto interactivo" se calcula de la siguiente forma; 


$$
\text { aij=(eij-e' ij)(rij-rio) }
$$

En lo referente a los datos, la información fue obtenida mediante el programa WITS (World Integrated Trade Solutions) del Banco Mundial y proviene de la base del COMTRADE, elaborada por las Naciones Unidas (2017). A partir de los productos identificados del sector textil bajo la Clasificación CIIU Rev.3, se han considerado las siguientes categorías de productos de cara a los ejercicios realizados; Hilatura, tejedura y acabado de productos textiles (categoría 171); Fabricación de artículos confeccionados de materiales textiles, excepto prendas de vestir (1721); Fabricación de tapices y alfombras (1722); Fabricación de cuerdas, cordeles, bramantes y redes (1723); Fabricación de otros productos textiles (1729); Fabricación de tejidos y artículos de punto y ganchillo (1730); y, Fabricación de prendas de vestir, excepto prendas de piel (1810). Los años de inicio y fin del periodo elegidos (1994 y 2015) han sido los primeros y últimos no atípicos en su comportamiento y con información completa, consistente y disponible para los países en cuestión, al momento de construir la base de información.

\section{Resultados}

Las figuras presentadas a continuación, sintetizan los aspectos más destacados para el análisis de la evolución del posicionamiento competitivo en los mercados de E.U. y la U.E. En estas figuras, con el fin de facilitar la interpretación, los diferenciales de exportación entre los países y el grupo de referencia se muestran en términos absolutos (en miles de millones de dólares) aunque las escalas puedan variar en función de los valores considerados. En el caso de México, la principal observación está asociada con un diferencial de exportaciones en el mercado de los E.U. explicado en su mayoría, por las variaciones del efecto competitivo, es decir por la diferencia registrada entre las tasas de crecimiento de las exportaciones del país con respecto a sus competidores, particularmente en la categoría 1810, concentradora de la actividad. Lo anterior implica una ausencia de cambio estructural en la composición de las ventas al extranjero en el periodo y un comercio basado en la profundización de las ventajas competitivas estáticas existentes al momento.

Los datos para la categoría concentradora de las ventas del textil mexicano al mercado de los E.U. (1810) desvelan un claro punto de ruptura alrededor del año 2000, en el que el efecto neto (diferencial de exportaciones) pasa de ser positivo a negativo, lo que refleja una pérdida de competitividad con respecto al grupo de referencia. Esta tendencia que se acelera hasta el 2005, y se atenúa después, sin embargo, mantiene su signo negativo hasta el final de la serie en 2015. Por su parte, el efecto estructural (EE) se mantiene, con excepción del año 2001, positivo de 1996 a 2007, tomando un valor cercano a cero a partir de 2008, dando cuenta así 
de un proceso trunco de especialización competitiva en dicho mercado. En consecuencia, el efecto interactivo (EI), positivo de 1996 a 1999, como resultado de la incipiente especialización en una categoría con ventaja competitiva, al amparo de los beneficios otorgados por las restricciones comerciales a la entrada del mercado norteamericano, se vuelve negativo el resto de la serie siguiendo la tendencia del efecto competitivo. Es de subrayar que entre 2002 y 2007, el país sigue incrementando la participación de las exportaciones de prendas de vestir en sus ventas sectoriales a E.U., a pesar de haber perdido su ventaja competitiva desde el año 2000, lo que da cuenta de la falta de una transformación estructural significativa del patrón de especialización en calidad de respuesta a la erosión competitiva registrada (Figura 3).

En cuanto al desempeño de China en el mercado de los E.U., al igual que para México, el efecto competitivo explica la mayor parte del diferencial de exportaciones, pero su ventaja competitiva se extiende a la mayoría de las categorías $(1711,1721,1723,1730$ y 1810). Este perfil exportador diversificado es sin embrago concomitante de una especialización competitiva en dos categorías principales de productos, mientras las ventas de la fabricación de prendas de vestir, actividad con tareas mayoritariamente de ensamblaje e intensivas en factor trabajo, concentran en 2015,54.5\% de sus exportaciones sectoriales a E.U., sus exportaciones en la categoría 1721, alcanzan a su vez, una cuota del mercado de E.U. de 59\% en ese mismo año. En forma diametralmente opuesta a México, los efectos neto y competitivo chinos, en estas categorías, registran una pérdida de competitividad con respecto al grupo de referencia entre 1994 y aproximadamente 1999, producto de las restricciones comerciales a la entrada del mercado de los E.U. No obstante, a partir del inicio de la liberalización mundial del sector en el 2000, estos efectos se vuelven definitivamente positivos e incrementan su valor hasta alcanzar puntos máximos alrededor del año 2005 (Figura 4).

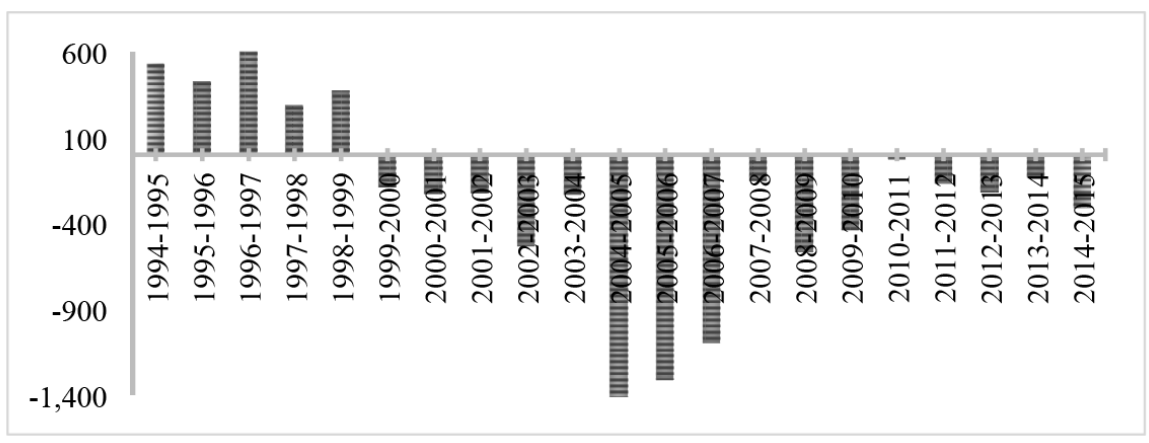

Figura 3.1: Efecto neto 


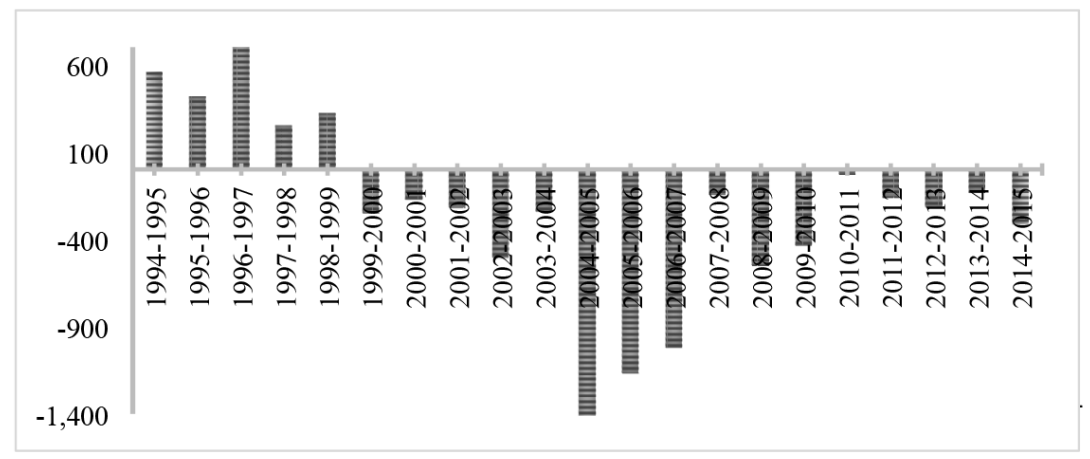

Figura 3.2: Efecto competitivo

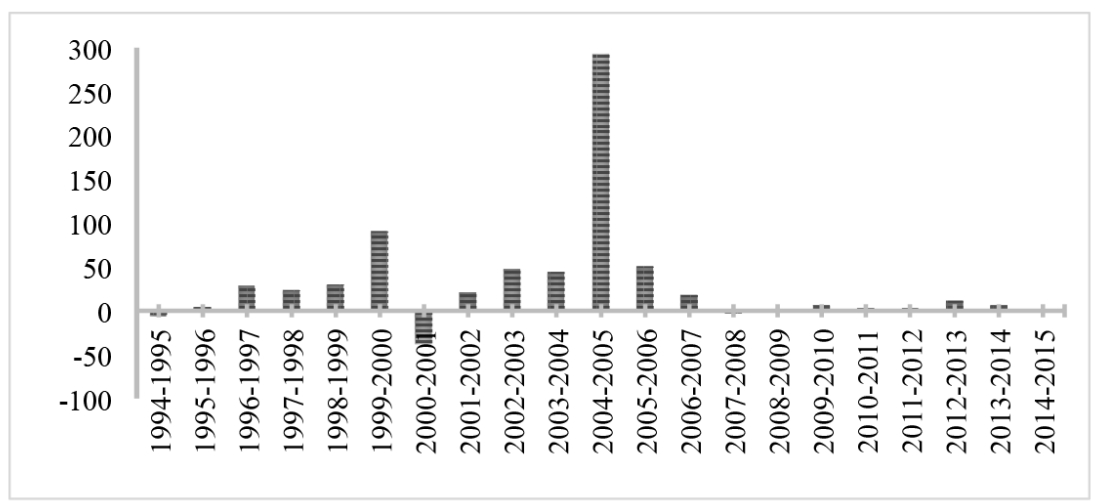

Figura 3.3: Efecto estructural

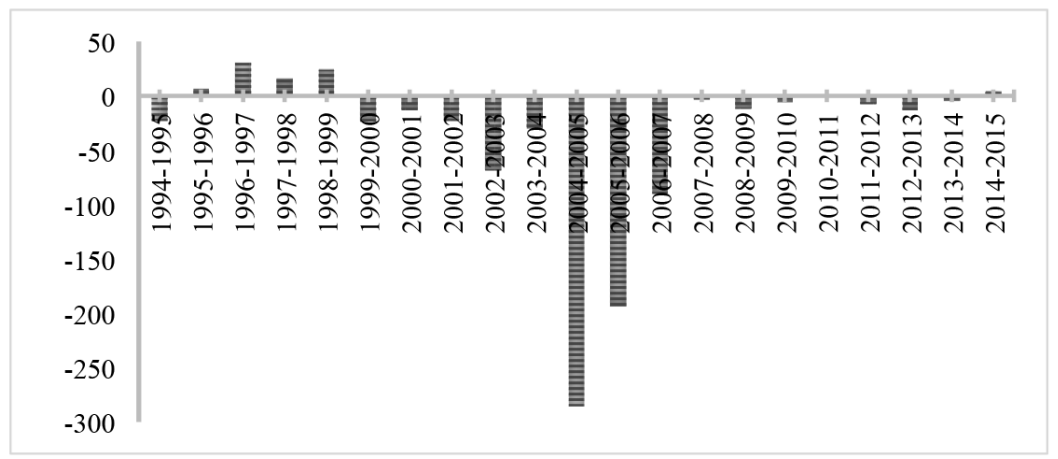

Figura 3.4: Efecto interactivo

Figura 3. Exportaciones mexicanas de prendas de vestir al mercado de los E.U. (millones de dólares) Fuente: Elaboración propiacon datos de ONU(2018),COMTRADE, descargados conel programaWITS delBanco Mundial La evidencia de una estrategia de posicionamiento competitivo basada en un escalamiento 
productivo de largo plazo es patente al analizar la evolución del EE para las categorías de exportación de China. A manera de ejemplo, mientras en el caso de los productos 1810, el EE es negativo entre 2001 y 2009, a pesar de que el país cuenta con una ventaja competitiva en el mercado de los E.U. en esos productos, el EE de la categoría 1721 es considerablemente positivo en un lapso similar (2002 y 2010) (con excepción de 2009). Lo anterior, resulta de un incremento relativo de la participación de los artículos de la categoría 1721, en detrimento de la parte de las mercancías de la 1810, en el total de exportaciones del sector al mercado de los E.U. En definitiva, se trata de un cambio del patrón de especialización chino que a la vez que reduce la vulnerabilidad de los ingresos de exportación, al fomentar la diversificación de los productos vendidos, promueve el crecimiento de categorías de mayor valor agregado o de aquéllas detectadas como dinámicas por su evolución en el mercado, tales como las ventas de artículos confeccionados de materiales textiles (1721). De hecho, muestra de su carácter dinámico, las exportaciones del grupo de referencia al mercado de los E.U. en la categoría 1721 pasan de representar 7.3\% de las ventas sectoriales del grupo a dicho mercado en 2001 a $13.7 \%$ en 2010 (Figura 4).

Otra categoría de productos cuya participación en las importaciones del mercado textil de los Estados Unidos se incrementa en el periodo de estudio (de 15.4\% en 1994 a $20.4 \%$ en 2015), es la Fabricación de tejidos y artículos de punto y ganchillo (1730). La Figura 5, ilustra los diferenciales de exportaciones en dicha categoría para México y sus competidores en el mercado de los E.U. con respecto al grupo en su conjunto. A pesar de que México incrementa la parte de las ventas de los productos 1730 en el total de sus exportaciones sectoriales (de $9.9 \%$ en 1994 a $19.7 \%$ en 2015), los gráficos revelan un desempeño inferior al de sus competidores a partir del año identificado como de ruptura en la serie (2000). Mientras Canadá e India muestran a su vez, una pérdida de competitividad relativa, en el primer caso, a partir del año 2000 resultado de la liberalización del mercado norteamericano, y en el segundo caso, entre 1994 y 2000, y de nuevo de forma más aguda a partir de 2008, China registra efectos netos positivos entre 2001 y 2015 con excepción de un solo año (2008). Los resultados se explican por una mayor competitividad de la economía China basada en márgenes intensivos, es decir, apuntalada por menores costos y precios más bajos de sus productos. Lo anterior permite al país asiático pasar de controlar $8.6 \%$ de la cuota del mercado de los E.U. en esta categoría en el 2000 a 33.9\% en 2015 (Tabla 2). En consecuencia, el efecto interactivo chino es de forma significativa, prácticamente nulo, a todo lo largo de la serie, y sus ganancias de mercado se explican en casi su totalidad por el efecto competitivo. 


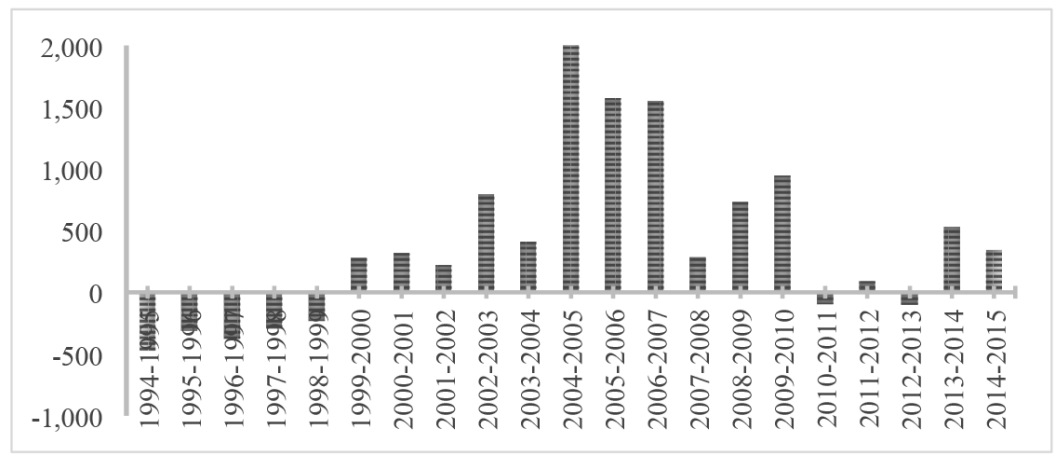

Figura 4.1: Efecto competitivo prendas de vestir

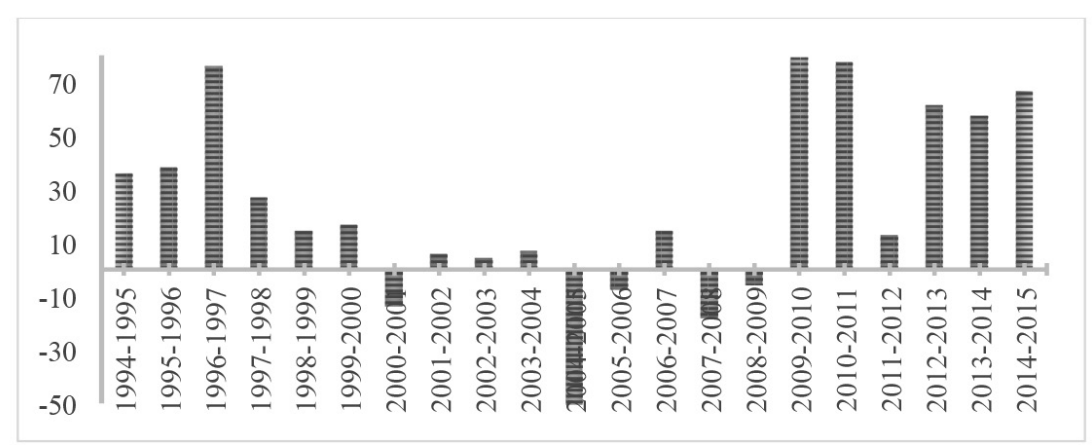

Figura 4.2: Efecto estructural prendas de vestir

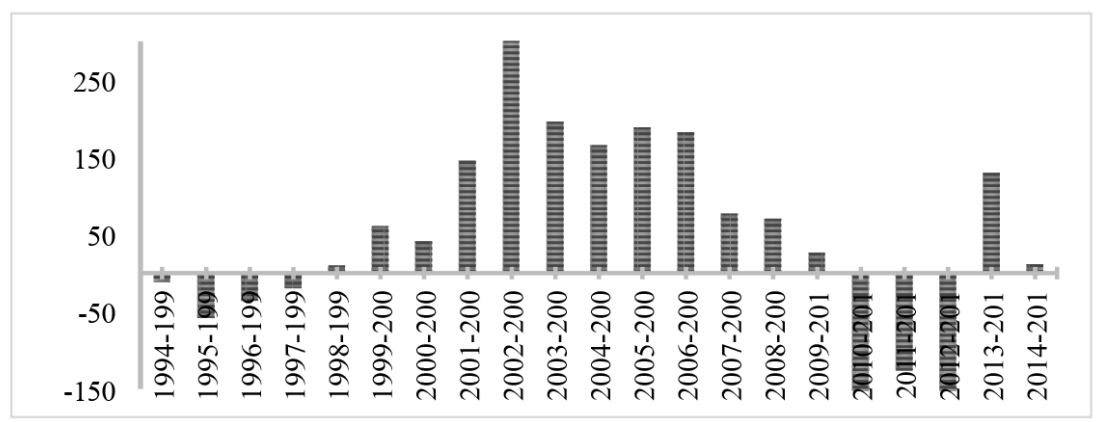

Figura 4.3: Efecto competitivo artículos de materiales textiles 


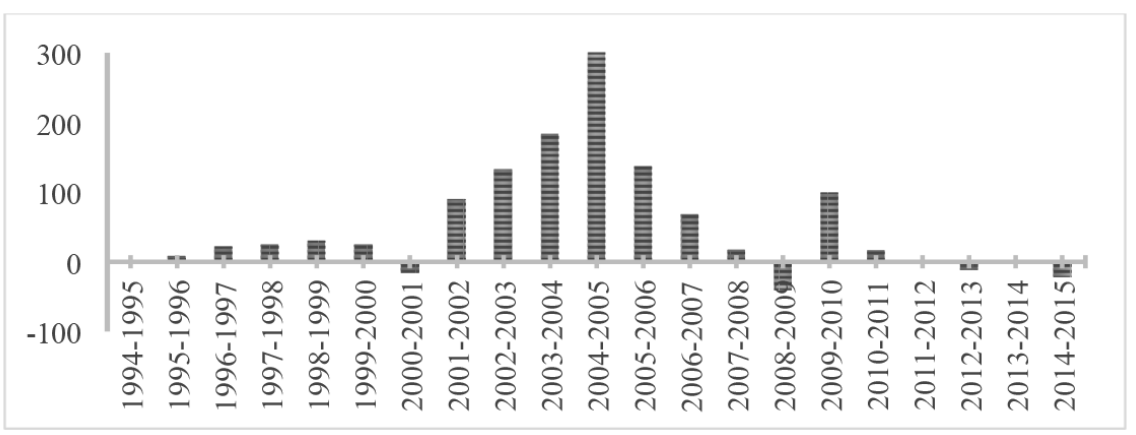

Figura 4.4: Efecto estructural artículos de materiales textiles

Figura 4. Exportaciones chinas de prendas de vestir y artículos de ma-

teriales textiles al mercado de los E.U. (millones de dólares)

Fuente: Elaboración propia con datos de ONU (2018), COMTRA-

DE, descargados con el programa WITS del Banco Mundial.

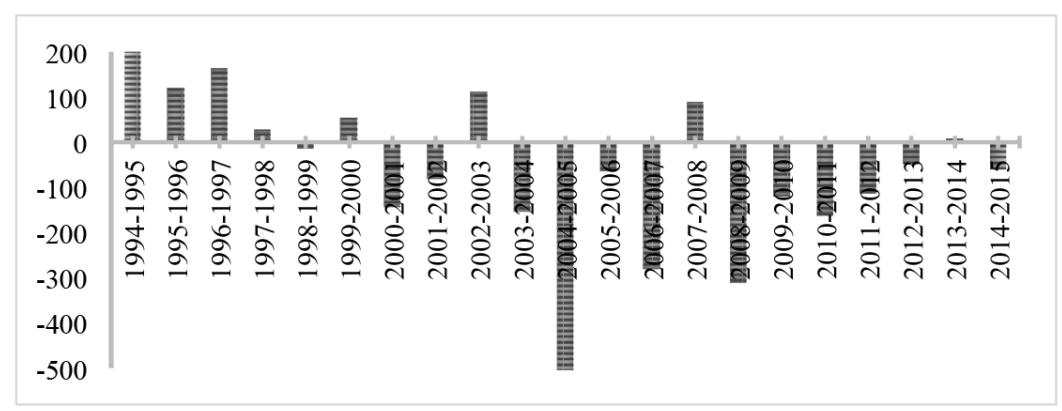

Figura 5.1: Efecto neto de México

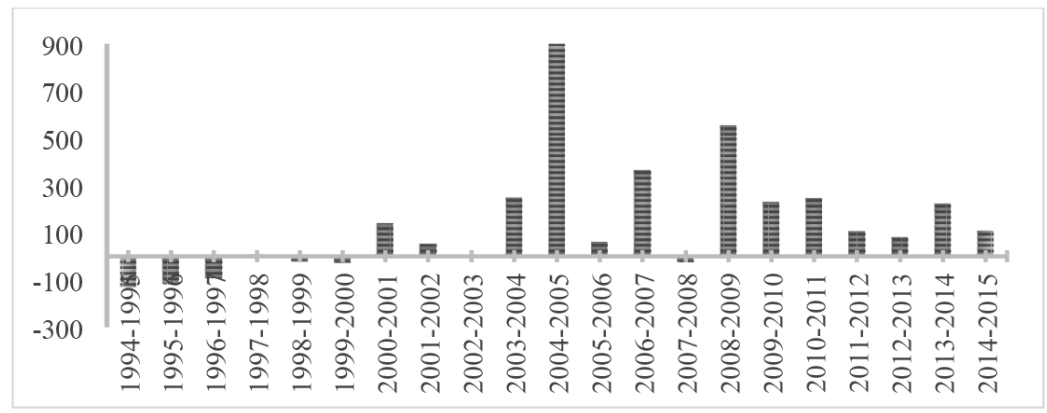

Figura 5.2: Efecto neto de China 


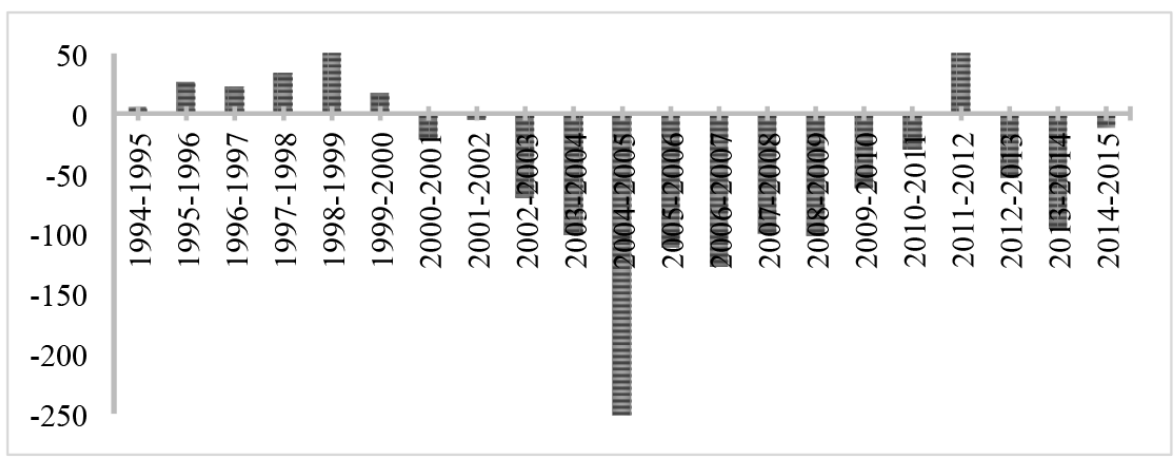

Figura 5.3: Efecto neto de Canadá

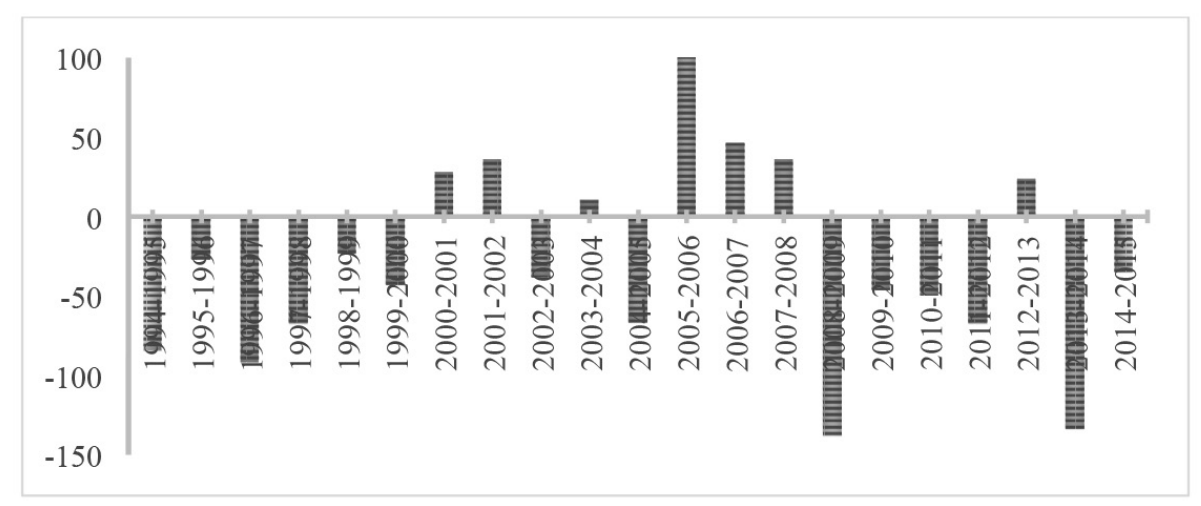

Figura 5.4: Efecto neto de India

Figura 5. Diferenciales de exportaciones de tejidos y artículos de punto y ganchillo al mercado de los E.U. por países (millones de dólares) Fuente: Elaboración propia con datos de ONU (2018), COMTRADE, descargados con el programa WITS del Banco Mundial.

En lo referente a las exportaciones del textil mexicano al mercado de la U.E. que representan en 2015 , solamente $1.2 \%$ del total sectorial, su estructura es muy volátil como resultado de la falta de una estrategia competitiva de largo plazo. En 1994, 40.4\% de las exportaciones a este destino son mercancía de la categoría que reagrupa el conjunto de insumos elaborados del sector (telas, hilos, y acabado de productos textiles (171)), cuyo proceso de fabricación suele ser más sofisticado tecnológicamente y menos fragmentado organizacionalmente, mientras $17.3 \%$ de estas ventas son prendas de vestir (1810), actividad por el contrario basada en la confección (ensamblado de piezas), que en calidad de eslabón final de la cadena suele presentar 
menores márgenes de rentabilidad y bajas barreras a la entrada, haciéndola especialmente accesible a países de menor desarrollo (Rivera, 2004). Para el año 2015, estos porcentajes se invierten dando cuenta de un cambio estructural regresivo en el que las exportaciones de la categoría 171 representan solamente $11.5 \%$ del total sectorial por $61.4 \%$ de las ventas de prendas de vestir. Prueba de la ausencia de un patrón de especialización exportador específico, son además los valores cercanos a cero tomados por el efecto interactivo en la categoría concentradora de la actividad (1810) a partir de 2006 (Figura 6).

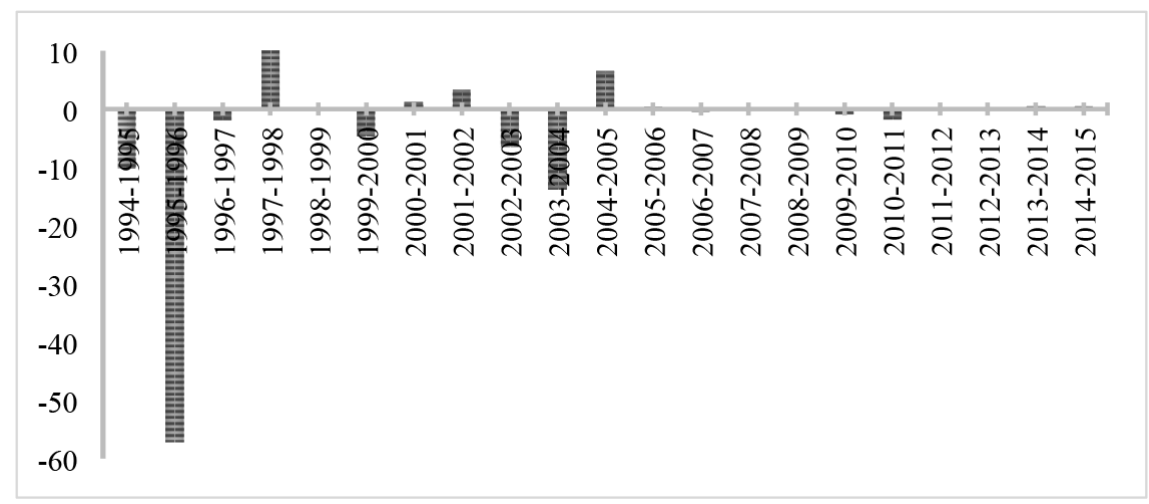

Figura 6. Efecto interactivo de las exportaciones mexicanas de prendas de vestir al mercado de la U.E. (millones de dólares)

Fuente: Elaboración propia con datos de ONU (2018), COMTRA-

DE, descargados con el programa WITS del Banco Mundial.

Por su parte, la Figura 7 muestra los diferenciales de exportaciones de prendas de vestir de México y sus principales competidores en el mercado de la U.E. en relación con el grupo de referencia. El desempeño irregular del textil mexicano en términos competitivos resulta del rol secundario que representa el mercado europeo para las exportaciones mexicanas, poniendo en relieve las posibilidades de un mercado de gran tamaño, en el que México no registra un importante rezago con respecto a sus competidores. China exhibe una vez más, un desempeño altamente competitivo a todo lo largo de la serie, apuntalado por elevados valores del efecto estructural que dan cuenta de una especialización exportadora en este tipo de productos y mercado. No obstante, mientras la India muestra un desempeño irregular con una especialización incipiente a partir del año 2010 en dicha categoría de productos, Turquía muestra una permanente pérdida de competitividad que se ve agravada por valores negativos de su efecto estructural.

En suma, los resultados obtenidos del análisis de la evolución del perfil de las exportaciones mexicanas en el mercado europeo muestran un posible cambio estructural regresivo en 
el que las ventas de prendas de vestir, originalmente destinadas a E.U., son re direccionados hacia la U.E. en detrimento de la profundización de las exportaciones relativas a los insumos elaborados. Lo anterior confirma tanto el rol secundario otorgado por el comercio exterior mexicano al mercado europeo como la ausencia de estrategias competitivas específicas para los distintos sectores y mercados. No obstante, y a pesar del irregular desempeño competitivo del textil mexicano en la U.E., los rasgos de este mercado se presentan como una oportunidad de diversificación y crecimiento, siempre y cuando se planteen desde la perspectiva de un escalamiento tecnológico y organizativo de largo plazo, cuyo objetivo sea la exportación de prendas de diseño original de alta gama. De lo contrario, superar la competencia de los países asiáticos y en especial de China, resultara inviable.

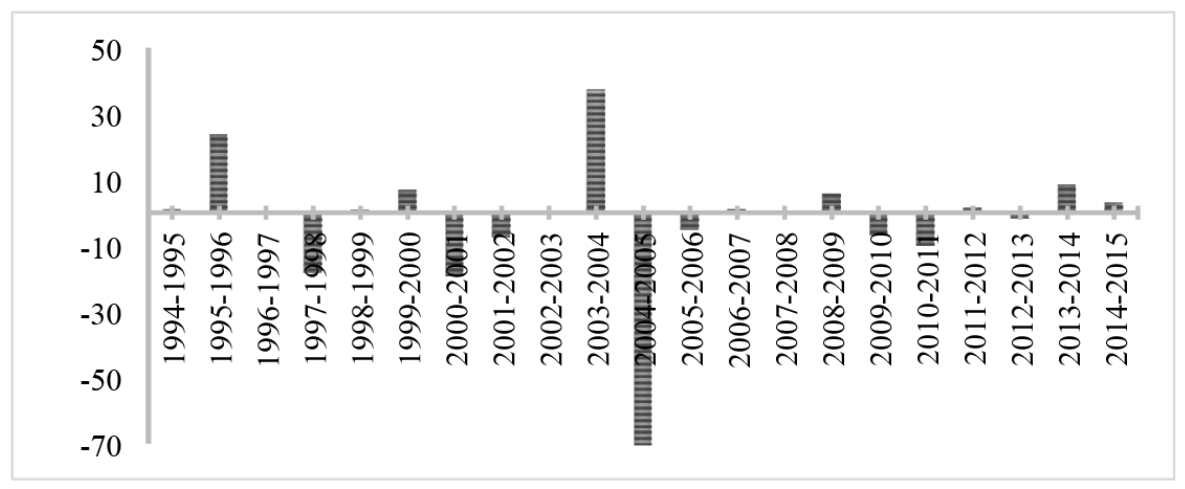

Figura 7.1: Efecto neto de México

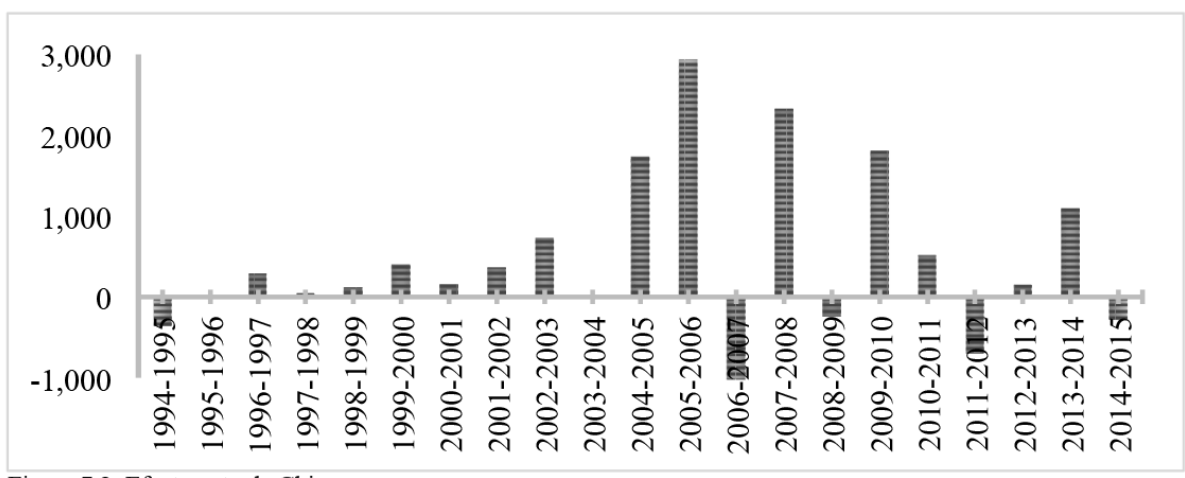

Figura 7.2: Efecto neto de China 


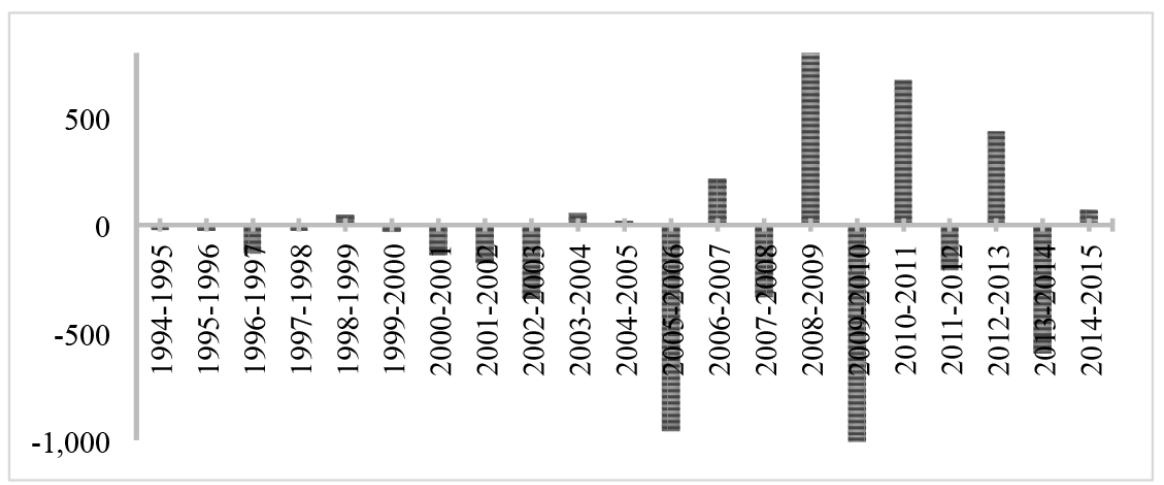

Figura 7.3: Efecto neto de India

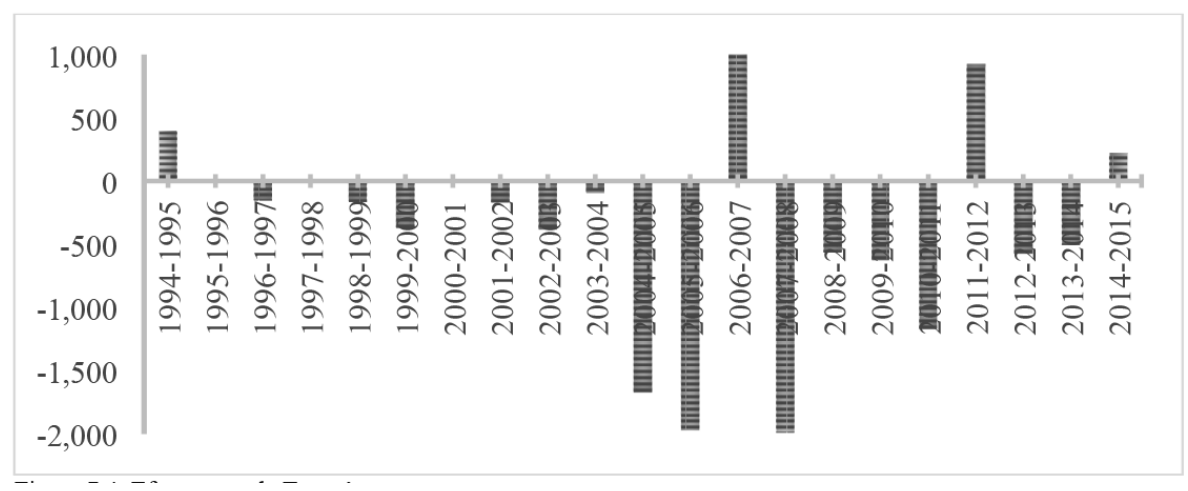

Figura 7.4: Efecto neto de Turquía

Figura 7. Diferenciales de exportaciones de prendas de vestir al mercado de la U.E. por países (millones de dólares)

Fuente: Elaboración propia con datos de ONU (2018), COMTRA-

DE, descargados con el programa WITS del Banco Mundial

\section{Conclusiones}

El "éxito" exportador del sector textil mexicano, a partir de la entrada en vigor del TLCAN, se gestó en el marco de una estrategia de reducción de costos globales por parte de grandes empresas transnacionales norteamericanas enfrentadas a la competencia de países asiáticos y de importantes restricciones comerciales a la entrada de sus competidores al mercado de los E.U. Los hallazgos derivados del presente trabajo permiten ubicar de forma clara un punto de ruptura de esta tendencia positiva en el 2000, año en el que se inicia la liberalización internacional de la industria. El "éxito" exportador registrado entre 1994 y 2000, al amparo del 
TLCAN, es concomitante de una elevada concentración de las exportaciones en las ventas de prendas de vestir, en dirección del mercado de los E.U., por parte de un número reducido de grandes productores proveedores de redes regionales de fabricación. Al respecto, la ausencia de una estrategia de posicionamiento competitivo de largo plazo para el sector, y en consecuencia de un escalamiento en términos tecnológicos y organizativos, resultó en una subsecuente pérdida de competitividad externa e incluso en un proceso de desindustrialización sectorial en México.

La aplicación de la técnica diferencial estructural a los datos de las exportaciones de México y sus competidores permite confirmar que el comercio del sector textil mexicano se basó en todo momento en la explotación de ventajas competitivas estáticas tales como la ubicación geográfica, la existencia de restricciones comerciales a los competidores en E.U., y los bajos salarios del país. Más aún, los ejercicios realizados permiten profundizar en cuanto a la inexistencia de un cambio estructural cualitativo relevante, que, ante la inminencia de la desaparición de los sistemas de cuotas en la industria, permitiera generar en respuesta, capacidades tendientes a desarrollar ventajas competitivas sustantivas en productos alternativos de mayor valor agregado. Comparativamente, el caso chino resulta ilustrativo, debido a un perfil competitivo basado en un inicio, como el de México, en bajos costos y la venta de prendas de vestir de baja gama, que fue sin embargo, diversificándose en dirección de productos de mayor sofisticación en una senda de escalamiento productivo que permitió el desarrollo de otro tipo de capacidades, y ventajas competitivas potenciales tales como la calidad, el acceso a insumos y transporte, la capacidad de diseño, y la adaptación de nuevas tecnologías, entre otros (Cárdenas y Dussel, 2007).

En términos de las implicaciones teóricas y prácticas del estudio, los hallazgos encontrados evidencian una tendencia competitiva del sector textil mexicano, en dirección de la pérdida de cuotas de mercado y, en definitiva, un posicionamiento de sus exportaciones, en segmentos de escaso valor agregado, en los que la competencia por parte de países de bajo nivel de desarrollo, irá en aumento y será definida en favor de los competidores con menores costos salariales. Este funcionamiento, implica, a su vez, una escasa generación de externalidades positivas para México y, en particular, la creación, en caso de haberla, de puestos de trabajo de baja calificación y pobres remuneraciones. De este diagnóstico, se desprende entonces, la necesidad de planificar desde el Estado, una estrategia integral tanto productiva como de comercio exterior, basada en el concepto del escalamiento productivo y tecnológico, que permita el desarrollo progresivo de capacidades, con el objetivo a mediano y largo plazo, de competir en los segmentos de alta gama de los principales mercados, a través del desarrollo de marcas propias.

Desde una perspectiva teórica, los resultados aquí encontrados implican también, el fracaso de un modelo económico ortodoxo, basado en una apertura comercial indiscrimi- 
nada, y sustentado en el concepto de la especialización productiva y comercial, a partir de ventajas competitivas determinadas por dotaciones factoriales, a la usanza de los modelos tradicionales explicativos del comercio exterior a la Heckscher-Ohlin. En este sentido, a raíz de los trabajos seminales de la nueva teoría del comercio internacional de Krugman (1980), diversos autores (Amsden, 2004; Dosi, Grazzi, y Moschella, 2015; Hidalgo, et al., 2007) han señalado las ventajas de generar, como el ejemplo chino lo demuestra, "nuevas" ventajas competitivas, a partir de medidas de política pública focalizadas en beneficio de productos o sectores dinámicos o nacientes. En síntesis, en el contexto de la polémica renegociación del TLCAN y a la luz de los resultados aquí alcanzados, el momento puede interpretarse como una oportunidad para que México ajuste los lineamientos de política pública existentes en dirección de un comercio exterior menos vulnerable, más diversificado, y que permita generar los empleos y el crecimiento económico que el país requiere.

\section{Agradecimientos}

Este artículo es producto de una estancia sabática de investigación apoyada por el programa PASPA-DGAPA, UNAM.

\section{Referencias}

Aditya, A., \& Acharyya, R. (2013). Export diversification, composition, and economic growth: Evidence from cross-country analysis. The Journal of International Trade \& Economic Development, 22(7), 959-992. https://doi.org/10.1080/09638199.2011.619009

Amsden, A. (2004). La sustitución de importaciones en las Industrias de alta tecnología. Prebisch renace en Asia. Revista de la CEPAL, Abril (82), 75-90. https://doi.org/10.18356/ eff646bf-en

Barff, R., \& Knight, P. (1988). Dynamic shift-share analysis. Growth and Change, 19(2), 1-10. https://doi.org/10.1111/j.1468-2257.1988.tb00465.x

Capdevielle, M. (2005). Globalización, especialización y heterogeneidad estructural en México. En M. Cimoli (Ed.), Heterogeneidad estructural, asimetrías tecnológicas y crecimiento en América Latina. (pp. 101-126). Santiago de Chile: Comisión Económica para América Latina y el Caribe (CEPAL)/Banco Interamericano de Desarrollo (BID). Disponible en: https://repositorio.cepal.org/bitstream/handle/11362/2799/1/S2005051_ es.pdf. Consultado: 10/02/2018. 
Capdevielle, M., Cimoli, M., \& Dutrenit, G. (1997). Specialization and technology in Mexico: A virtual pattern of development and competitiveness? Working Paper No. IR-97-016, IIASA. Disponible en: http://pure.iiasa.ac.at/id/eprint/5275/ Consultado: 12/12/2018.

Cárdenas, H., \& Dussel, E. (2007). México y China en la cadena hilo-textil-confección en el mercado de Estados Unidos. Comercio Exterior, 57(7), 530-545. Disponible en https:// www.dusselpeters.com/35.pdf. Consultado: 18/02/2018.

Dosi, G., Grazzi, M., \& Moschella, D. (2015). Technology and costs in international competitiveness: From countries and sectors to firms. Research Policy, 44(10), 1795-1814. https://doi.org/10.1016/j.respol.2015.05.012

García de León, G. (2008). La inserción de México en la arquitectura cambiante de redes del suministro del vestido hacia Estados Unidos (1985-2003). Distrito Federal: IIEc. UNAM - Universidad de Sonora.

García de León, G. (2009). Estrategias corporativas y reconfiguración de las cadenas de proveeduría del vestido hacia Estados Unidos: El caso de la firma Levi Strauss \& Co. Estudios fronterizos, 10(20), 103-128. https://doi.org/10.21670/ref

González, M. (2004). Efectos del TLCAN en la industria textil y de la confección mexicana.

En M. González, I. Rueda, \& Simón N. (Eds.), La industria de la confección en México y China ante la globalización. (pp. 91-115). Distrito Federal: UNAM - Porrúa.

Hidalgo, C., Klinger, B., Barabási, A., \& Hausmann, R. (2007). The product space conditions the Development of Nations. Science, 317(5837), 482-487. https://doi.org/10.1126/ science. 1144581

Hidalgo, C., \& Hausmann, R. (2009). The building blocks of economic complexity. Proceedings of the National Academy of Sciences, 106(26), 10570-10575. https://doi. org/10.1073/pnas.0900943106

Krugman, P. (1980). Scale economies, product differentiation, and the pattern of trade. The American Economic Review, 70(5), 950-959.

Monetary Authority of Singapore. (1998). Growth in Singapore's Export Markets, 199196: A Shift-Share Analysis, Occasional Paper No. 4, Economics Department, Monetary Authority of Singapore. Disponible en: https:/www.mas.gov.sg/publications/staff-papers/1998/mas-occasional-papers-no--4--feb-1998. Consultado: 28/03/2019.

Morales, J., Parker, M., \& Saavedra, E. (2010). La experiencia maquiladora en La Laguna. Distrito Federal: Mimeo.

Naciones Unidas. (2017). UN COMTRADE (United Nations Commodity Trade Statistics Database) [Base de Datos]. Disponible en UN Comtrade Database website: https://wits. worldbank.org Consultado: 7/09/2018.

Puyana, A., \& Romero, J. (2006). Hacia una evaluación de los efectos multiplicadores de la actividad maquiladora. Estudios Sociológicos, 24(70), 65-97. Disponible en: https:// www-jstor-org.pbidi.unam.mx:2443/stable/40421025. Consultado: 25/10/2018.

Rivera, M. (2004). La reestructuración de la industria de la confección en México. En M. González, I. Rueda, \& Simón N. (Eds.), La industria de la confección en México y China 
ante la globalización. (pp. 69-89). Distrito Federal: UNAM - Porrúa.

Romero, J., Puyana, A., \& Dieck, L. (2005). Apertura comercial, productividad, competitividad e ingreso: La experiencia mexicana de 1980 a 2000. Investigación Económica, 64(252), 63-121. http://dx.doi.org/10.22201/fe.01851667p.2018.304

Stanley, D., \& Bunnag, S. (2001). A new look at the benefits of diversification: Lessons from Central America. Applied Economics, 33(11), 1369-1383. https://doi. org/10.1080/00036840010007498

Strobl, E., Bertinelli, L., \& Heinen, A. (2009). Export diversification and price uncertainty in developing countries: A portfolio theory approach, SSRN Scholarly Paper No. ID 1327928, Social Science Research Network. Disponible en: http://dx.doi.org/10.2139/ ssrn.1327928 Consultado: 25/10/2018.

Taboada, E. (2000). El reto competitivo de las empresas nacionales del sector textil vestido. Análisis Económico, 15(32), 173-191. https://doi.org/10.24275/uam/azc/dcsh/ae

Timmer, P. (1988). The agricultural transformation. En H. Chenery y T. Srinivasan (Eds.), Handbook of development economics, vol. 1. ( pp. 275-331). Elsevier: https://doi. org/10.1016/S1573-4471(88)01011-3

Vázquez, R. (2012). Is it possible to upgrade in global value chains? A comparison between industrial policy in Mexico and the Asian experience. Journal of Globalization, Competitiveness \& Governability, 6(3), 119-130. https://doi.org/10.3232/GCG.2012.V6.N3.07

Vidal, G. (2014). Manufacturing, industry and growth in Mexico. International Journal of Political Economy, 43(4), 63-81. https://doi.org/10.1080/08911916.2014.1002688

Wilson, P., Chem, T., Ping, T., \& Robinson, E. (2005). Assessing Singapore's export competitiveness through dynamic shift-share analysis. ASEAN Economic Bulletin, 22(2), 160-185. https://doi.org/10.1355/AE22-2C

Yasin, M., Alavi, J., \& Lisboa, J. (2004). A shift-share analysis approach to understanding the dynamic of the Portuguese tourism market. Journal of Travel \& Tourism Marketing, 17(4), 11-22. https://doi.org/10.1300/J073v17n04_02 